\title{
Determine the Impacts of Uneven Distribution of Resources on Major Choosing of Students from Different Regions in US
}

\begin{abstract}
Qianyun Yao*
University of Washington Bothell

${ }^{*}$ Corresponding author.Email: qiana801@uw.edu

ABSTRACT

The distribution of resources in the US for minority students and African-American students has been substantially unequal and separate. Many people do not know that the education system of the US is one of the most unfair in the world. Many students in the US face challenges in choosing a major because of the uneven distribution of resources in the different regions of the US. This research paper carries out research on the impacts of the uneven distribution of resources in the US on students choosing a major. The impacts include lack of motivation for the students, high levels of poverty of the student's families, and lack of learning resources. These impacts result from the uneven allocation of learning resources to some areas in the US making the schools in such areas have insufficient learning resources. These in turn affect the performance of the students negatively and in the end, such students face a lot of challenges when choosing majors.
\end{abstract}

Keywords: High poverty schools, Low poverty schools, Minority students, African-Americans, Hispanics.

\section{INTRODUCTION}

Students with enough learning resources such as books, teachers' attention, enough family income, and other learning materials typically have more opportunities to learn and use them perfectly to succeed in their academics. Students with little resources face a lot of challenges in succeeding in their academics compared to those with enough resources [The Commonwealth Institute. 2021]. This in turn creates a great academic gap between the two types of students from different social classes. Chances are high that these students with little resources fail due to the lack of learning resources. With enough and the right resources, these students can do better academically. It is therefore sad that some students fail due to the uneven distribution of learning resources. For countries with limited resources, the country should decide how the available resources can be distributed efficiently to ensure the overall student achievement is maximized [Canadian Centre for Policy Alternatives. 2021].

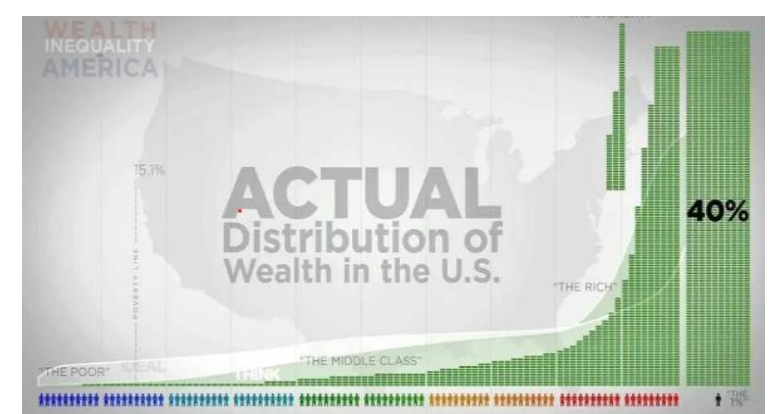

Figure 1

The distribution of resources in US for minority students and African American students has been substantially unequal and separate as illustrated in the figure above. Many people do not know that the education system of US is one of the most unfair in the world. In US, many students get different learning opportunities due to their social status. In US, minority and poor students are highly populated in poorly funded schools. Most of these schools are found in the rural areas or central cities and they are also funded at levels that are substantially below those of the neighboring suburban districts. There is a significant gap between the high and low class in US and the gap is continuously 
growing [ArcGIS StoryMaps. 2021]. Additionally, the share that the middle-income people hold is falling as illustrated below.

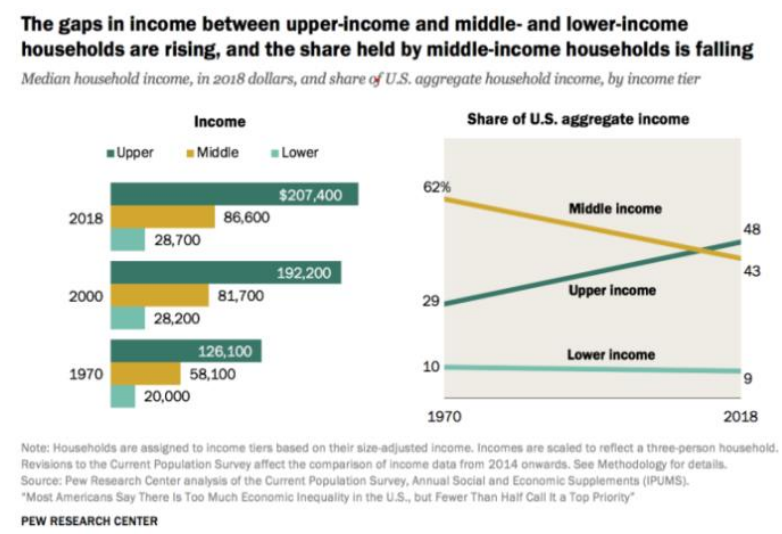

Figure 2

\section{RESEARCH GAP}

There is a current research gap on the impacts of low funding in the high poverty schools to students and teachers. In order to fill this gap, some questions were raised in the research. They include, what are the effects of low funding on teachers as well as students in highpoverty schools? What are the academic patterns of students in high poverty schools? What challenges do teachers in low funded schools face as well as the students and what are the effects of those challenges? To answer these questions, interviews and questionnaires were issued to the authorities and teachers in the lowly funded schools. It is important to study these questions because they help understand how low funding affects students in high poverty schools as well as teachers which later brings a difference in performance between students from high poverty schools and high-funded schools.

As a result of unequal distribution of resources to students from different regions in US, persistent differences in scores from tests and enrolment in college between students from more financially stable families and those from low-income families have been evident. This has led to many impacts such as increased cases of school dropouts, increased crime rates, and increased cases of unemployment. This has been a result of frustration which has made many students give up on their studies and drop out of school. This research discusses the impacts of unequal distribution of resources in US to students from different regions choosing majors.

\section{LITERATURE REVIEW}

The wealth gap existing between white and black families in US remains large though the Black families have gained wealth in terms of dollars according to a report in 2020 by Federal Reserve Bank of St. Louis
[Kent]. A typical non-Hispanic Black family in 2019 had a wealth of about $\$ 23,000$. That is an increase from that of 2016 which was $\$ 17,000$ [Kent]. However, there is still a significant gap between the wealth of the White and Black families as illustrated below.

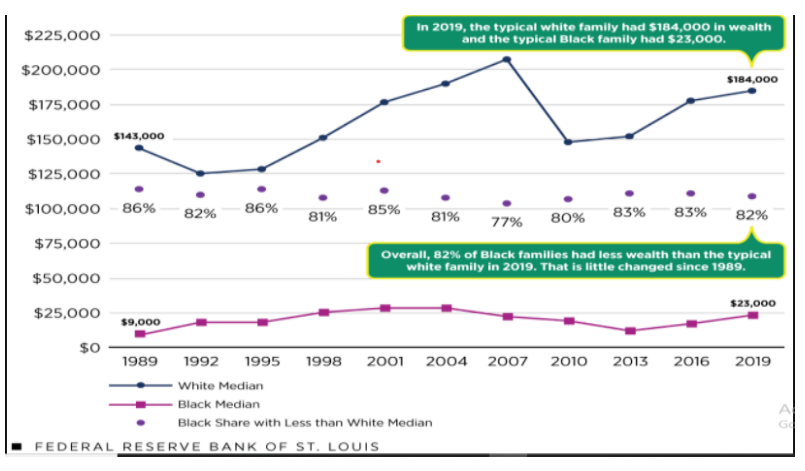

Figure 3 The Median Gap in Wealth between White and Black Families in US

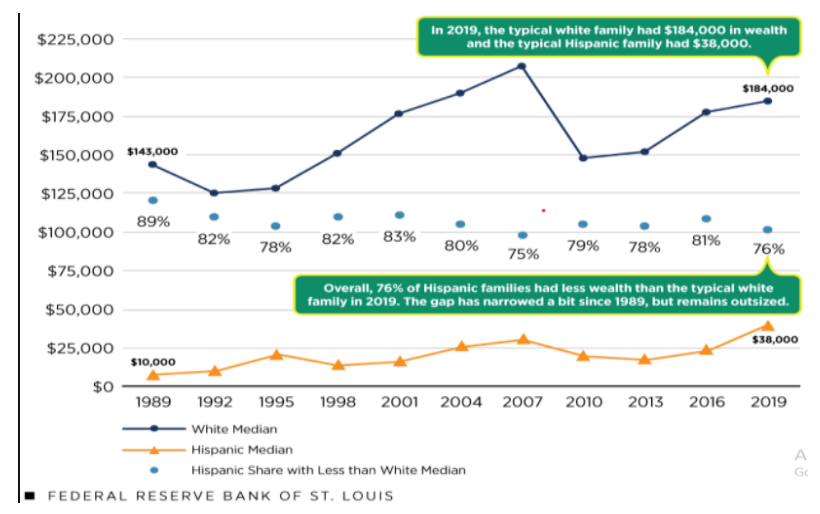

Figure 4 The Median Gap in Wealth between White and Hispanic Families in US

In recent decades, the growth in income has favored the upper-income households. However, the middleclass in US is shrinking. As a result, majority of the aggregate income of the nation is currently going to upper-income households while the share the lower and middle households get is falling.

Students in lowly funded schools have instructors and teachers who are less experienced compared to those well-funded, have less access to high-level math, science, and advanced placement courses. The highpoverty schools have lower levels of local and state spending on instructors as well as other instructional materials. In the 2013-2014 school year, the average salary of a teacher in the high poverty schools was around $\$ 46,000$ compared to low poverty schools which were $\$ 57,000$ [The Commonwealth Institute. 2021]. It is the students who suffer the effects of such disparities and they have resulted in worse outcomes in terms of school performance, attendance, and graduation rates. The state-accredited for only one-third of the high 
poverty schools. In Virginia, the most deprived students of the opportunity to pursue their career ambitions and goals were largely Hispanic and Black students. This is evident because students of color make the largest population of high-poverty schools as illustrated below. Out of six students of color, one student attended a highpoverty school in Virginia, in the 2012-2014 school year [The Commonwealth Institute. 2021]. This was also the case with the black students, with one out of every five Black students attending high poverty schools. This is tragic compared to only 3 percent of White students.

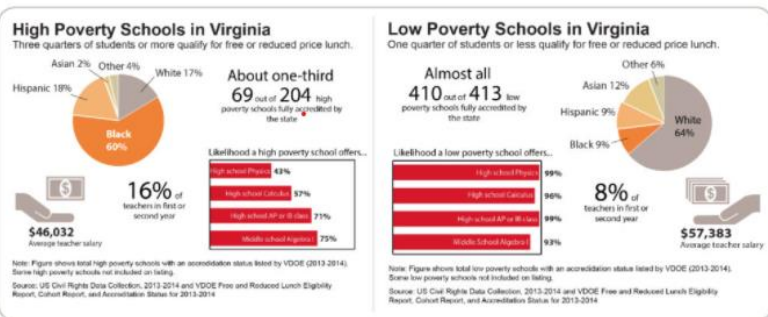

\section{Figure 5}

In terms of resources and opportunities for students in high poverty schools, the students in high poverty schools had less experienced teachers. The majority of middle schools that have low poverty concentrations offered Algebra I, which is $93 \%$. On the other hand, $75 \%$ which is only three-quarters of schools with high concentrations of poverty were offering this crucial course in building foundational skills in Math and making a gateway to high levels of math [The Commonwealth Institute. 2021]. Some of the outcomes of uneven distribution of resources have been poor performances, school dropouts, and low graduation numbers.

In order to ensure equality, some of the measures that can be taken include financial support to lowly funded schools, promotion of local enrollment policies, and provision of private school options. The state has a program known as the At-Risk Add-On which aims at ensuring additional assistance from the state to school divisions. These funds can be utilized by schools in offering competitive salaries to teach to attract and retain experienced teachers or provide more instruction to students who are struggling. School leaders should promote enrollment policies that support diverse and balanced public schools. This can be done by the implementation of controlled choice enrollment allowing parents to select public schools they would like their children to attend. This strategy can help increase diversity in public schools.

\section{METHODOLOGY}

This research involved measuring inequality in different schools in US. This research involves different schools in the United States from different regions. The schools used in this research are public schools whose information can be accessed from the VDOE student enrolment data, and the Civil Rights Data Collection from the Office of Civil Rights. The sources of data for this research included the results from research by other authors in different websites, journals, and articles on the unequal distribution of resources to students and the effects of the same. The data collected were from different sources and was recorded to draw conclusions from the results. The collection of data focused on the different inequalities in the distribution of resources and their effects. Data collection also involved observations where different schools were considered and observed the diversity in those schools. Data was also collected from enrolment reports in US colleges and the pattern of enrolment was noted. Schools with low funding were also considered by checking the number of students who dropped out as well as the results of the students in general.

Schools with enough and high funding from the government were also considered. Using open-ended questionnaires and interviews, the school authorities were questioned on the performance of their students as well as the general performance of the students. They were also asked about the level of experience of their teachers. The authorities were also asked about their enrolment policies, qualifications, and considerations. The data was taken from schools that were well funded by the state and those that were lowly funded by the state. The data was recorded differently for later comparisons. In the lowly funded schools, interviews and questionnaires were issued to the authorities and teachers. They were asked about the effects of the low funding on the students as well as the teachers. They were also asked about the academic pattern of the students and their enrolment policies. They also stated the challenges they faced as well as the students and the effects of those challenges. The information was recorded for later discussion and analysis.

\section{RESULTS}

\begin{tabular}{lc} 
Student characteristics & $\begin{array}{c}\text { Share of } \\
\text { total }\end{array}$ \\
\hline White & $51.5 \%$ \\
Black & $13.7 \%$ \\
Hispanic & $24.9 \%$ \\
$\begin{array}{l}\text { Hispanic English-language } \\
\text { learner (ELL) }\end{array}$ & $11.4 \%$ \\
Hispanic English speaker & $12.6 \%$ \\
Asian & $4.4 \%$ \\
Other & $5.5 \%$ \\
Girl & $48.5 \%$ \\
Has a disability & $20.5 \%$
\end{tabular}

Figure 6 
The research found that in 2020, there was an uneven distribution of resources in different regions in US. Schools in some areas were lowly funded compared to schools in other areas [Soeonline.American.Edu, 2021]. It was found that the schools in US with the highest number of Native, Latino, or Black American students got around $\$ 1,800$ dollars lesser per student compared to the districts with schools with high populations of White students [Soeonline.American.Edu, 2021]. The funding difference between high-income and low-income areas was found to be $\$ 1,000$ for each student [Soeonline.American.Edu, 2021]. The table above compares resource distribution in schools in 2010 in US.

The schools that were well funded had enough learning materials as well as experienced teachers. The well-funded schools had a higher population of white students compared to students of color. On the other hand, the lowly-funded schools had fewer learning materials and their teachers were less experienced. These schools lacked some of the essential learning materials like books. These schools got little funding from the state and most of its population was characterized by students of color such as Black Americans and the Latin. In the 2013-2014 school year, the average salary of a teacher in the high poverty schools was around $\$ 46,000$ while that at low poverty schools was $\$ 57,000$ [The Commonwealth Institute. 2021]. In Virginia, out of six students of color, one student attended a high poverty school in the 2012-2014 school year. This was also the case with the black students, with one out of every five Black students attending high poverty schools. On the other hand, only 3 percent of the students in high poverty schools were White students. The research also found a high number of dropouts in high-poverty schools.

In 2012, the United States reported 1.1 million members not earning their diplomas because of school dropout cases. The table below compares school dropouts according to different races.

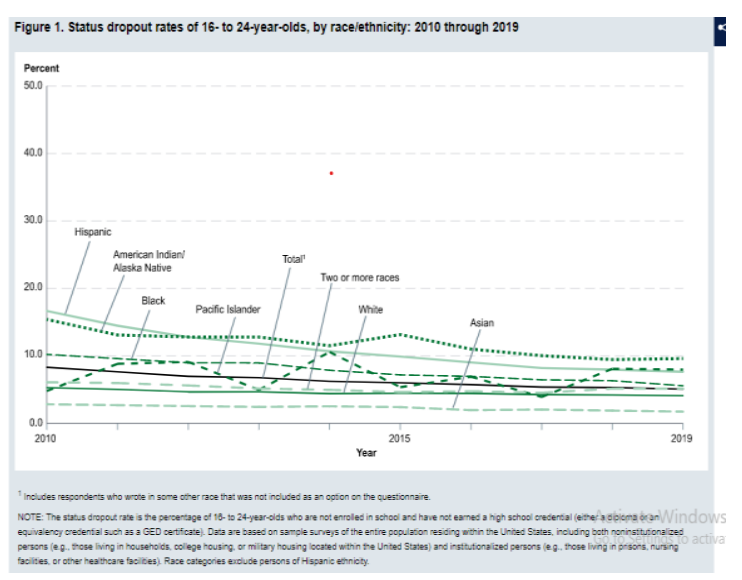

Figure 7
A report also indicated that child poverty was a great challenge in US with over $20 \%$ of students living in poor families [The Commonwealth Institute. 2021]. The report also stated that the rates of poverty for Hispanic and Black families were three times that of White families. Neighborhoods with a high population of African-Americans and Hispanic residents were characterized by high levels of poor health, joblessness, substance use, family instability, poverty, crime, and welfare dependency.

The impacts of uneven funding that were reported by the interviewees, the answers from the questionnaires, and other secondary sources like journals include high rates of school dropouts, increased crime rates, and increased cases of unemployment. The number of students who graduate in the selected schools also indicated gaps with the high poverty schools reporting the highest number of students who did not graduate due to dropping out of school. The low poverty schools reported fewer cases of students who did not graduate and the dropout cases were also fewer than the high poverty schools. Students in high poverty schools reported poor results compared to those in low poverty schools who had good overall performances.

Some of the challenges that were communicated by school authorities in high-poverty schools include lack of motivation for the students, high levels of poverty of the student's families, and lack of learning resources. There was also a trend of poor academic performance by students of color compared to White students as illustrated below.

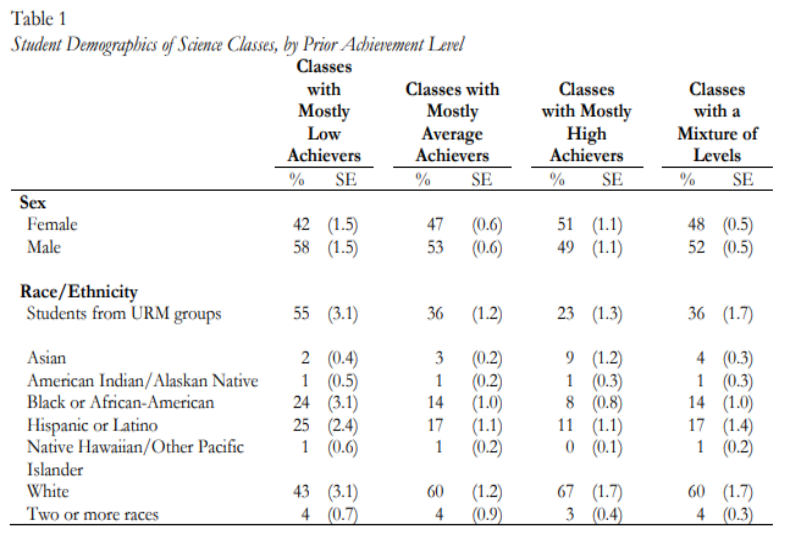

Figure 8

The respondents also stated that there were high cases of missing school in the high poverty schools. On the other hand, low poverty schools reported availability of learning materials, highly motivated students, and low levels of poverty with most students coming from economically stable families, and good school attendance. 


\section{DISCUSSION}

The distribution of resources in US for minority students and African-American students has been substantially unequal and separate. In US, many students routinely get different learning opportunities because of their social status. This is evident from the results of the research where the schools with many students of color get little funding and resources from the state while schools with high populations of white students get enough resources from the government and enough funding [Soeonline.American.Edu, 2021]. This makes the students from poor families have challenges accessing learning resources which affect their academic performance negatively. As a result, the students may not qualify to enroll in the best institutions after graduation and may also fail to qualify to take their dream careers. As a result, this affects the students from poor families negatively when majoring in different careers. On the other hand, students with enough learning resources have a high chance of performing well in their academics and qualify to be enrolled in the best colleges and universities, and pursue their dream careers.

Unequal distribution of learning resources has also led to an increase of school dropouts with the majority being students from high poverty schools. The students from high poverty schools have few learning materials which makes it challenging for them to succeed in their academics [Canadian Centre for Policy Alternatives. 2021]. Due to the lack of learning materials, many students fail in their tests which is a great discouragement. As a result of this discouragement, the students lose the morale to study, and finally, they drop out of school. On the other hand, students from schools with enough resources are highly motivated to learn due to the availability of learning resources, and therefore, dropout cases are fewer. Most of the school dropouts are students of color because they come from poor families and cannot afford the best schools with enough learning resources. On the other hand, the White students come from economically stable families, and therefore, they can easily afford schools with enough learning resources.

The other effect of the uneven distribution of learning resources is an increase in unemployment cases [Canadian Centre for Policy Alternatives. 2021]. As a result of the unequal distribution of resources, many students drop out of school before even majoring in their dream courses. Since the dropouts are not qualified for many top jobs, they end up jobless. This is evident from the high cases of joblessness in the poor communities especially those with high populations of Black Americans and Hispanics. On the other hand, there are low cases of joblessness in the White American communities because the students from those communities have enough learning resources and therefore, after graduation, they can major in their dream careers and later get good jobs.

Increased crime rates are the other impact of uneven distribution of resources on students. High cases of crime rates have been reported that can be related to the uneven allocation of resources [Canadian Centre for Policy Alternatives. 2021]. When the government does not distribute resources evenly, some communities will be left in poverty. Students from poor families face a lot of challenges in their education as a result of poverty. Students from poor families cannot afford the best schools with the best learning resources. As a result, those students attend high-poverty schools where resources are limited. As a result, these students lack the motivation to continue with their studies and drop out of school. Since they are not qualified for many jobs, these dropouts end up being jobless. After looking for jobs without success, poverty and basic needs may force them to get into crime. Joblessness is stressful because the students need a way to earn money to meet their daily needs. When jobs are not available, they get into crime to meet these needs. Some get into drug and substance abuse due to the stress and depression they face in the streets as they try to make ends meet.

\section{CONCLUSION}

This paper has discussed the effects of uneven distribution of resources on students which include lack of motivation for the students, high levels of poverty of the students' families, and lack of learning resources. The Uneven distribution of resources in US has many negative effects on students from different areas in choosing majors. The uneven distribution of resources affects some regions and the students from those areas experience the effects of the uneven distribution of resources. When resources are not evenly distributed, the students face a lot of challenges in school and the impacts have an overall effect on their performance. As a result, the student may not qualify to enroll for their preferred majors in college or university. Some of the challenges that the students face due to unequal distribution of resources have been discussed and include poverty, lack of learning materials, and lack of motivation to learn.

On the other hand, students from the areas that get enough resources are affected positively because they can access the learning materials they need as opposed to those with no or little resources. As a result, the availability of learning resources motivates them to succeed in their academics. These students can easily enroll in the majors of their choice. This creates a big gap between the poor and the rich. 


\section{REFERENCES}

[1] ArcGIS StoryMaps. (2021). Uneven Wealth Distribution in the United States Retrieved 31 October 2021, from https://storymaps.arcgis.com/stories/ad7fca0337024 e7fa8e9d88cdf4ff158

[2] Canadian Centre for Policy Alternatives. (2021). All social and economic problems caused by an unfair distribution of wealth. Retrieved 31 October 2021, from https://www.policyalternatives.ca/publications/com mentary/all-social-and-economic-problems-causedunfair-distribution-wealth

[3] Economic Policy Institute. (2021). Education inequalities at the school starting gate: Gaps, trends, and strategies to address them. Retrieved 31 October 2021, from https://www.epi.org/publication/educationinequalities-at-the-school-starting-gate/

[4] Edutopia. (2021) How Does Poverty Influence Learning? Retrieved 30 October 2021, from https://www.edutopia.org/blog/how-does-povertyinfluence-learning-william-parrett-kathleen-budge
[5] Kent, Anna Hernandez. "Has Wealth Inequality In America Changed Over Time? Here Are Key Statistics". Federal Reserve Bank Of S. Louis, 2021, https://www.stlouisfed.org/openvault/2020/december/has-wealth-inequalitychanged-over-time-key-statistics. Accessed 14 Nov 2021.

[6] Soeonline.American.Edu, 2021 Home, Online et al. "Inequality In Public School Funding: Key Issues \& Solutions For Closing The Gap"., https://soeonline.american.edu/blog/inequality-inpublic-school-funding

[7] The Commonwealth Institute. (2021). Unequal Opportunities: Fewer Resources, Worse Outcomes for Students in Schools with Concentrated Poverty - The Commonwealth Institute. Retrieved 30 October 2021, from https://thecommonwealthinstitute.org/research/uneq ual-opportunities-fewer-resources-worse-outcomesfor-students-in-schools-with-concentrated-poverty/

[8] Trends in U.S. income and wealth inequality. (2021). Retrieved 14 November 2021, from https://www.pewresearch.org/socialtrends/2020/01/09/trends-in-income-and-wealthinequality/ 